\title{
Immune reconstitution after alemtuzumab therapy for multiple sclerosis triggering Graves' orbitopathy: a case series
}

\author{
Jonathan C. P. Roos ${ }^{1,2} \cdot$ Carla Moran $^{3} \cdot$ V. Krishna Chatterjee ${ }^{3} \cdot$ Joanne Jones $^{2} \cdot$ Alasdair Coles $^{2} \cdot$ Rachna Murthy $^{1,2}$
}

Received: 5 November 2018 / Accepted: 6 November 2018 / Published online: 29 November 2018

(C) The Royal College of Ophthalmologists 2018

\begin{abstract}
Alemtuzumab—a monoclonal antibody targeting the CD52 glycoprotein expressed by most mature leucocytes—effectively decreases relapse rate and disability progression in early, relapsing-remitting multiple sclerosis (MS). However, secondary autoimmune disorders complicate therapy in nearly $50 \%$ of treated patients, with Graves' disease being the most common. Rarely, thyroid eye disease (TED) ensues; only seven such cases have been reported. Our aim was to analyse the largest series of MS patients developing thyroid eye disease after alemtuzumab treatment. We performed a retrospective chart review of MS patients treated with alemtuzumab (1995-2018) and subsequently identified by their treating physicians as having developed TED and referred to our ophthalmology service. As an original trial centre for alemtuzumab, our hospital has treated approximately $162 \mathrm{MS}$ patients with this novel therapy. In total, $71(44 \%)$ developed thyroid dysfunction, most of whom (87\%) developed Graves' disease, with ten (16\%) referred for ophthalmological evaluation. Two developed active orbitopathy following radioiodine treatment; one occurred after cessation of anti-thyroid drug treatment. Three developed sight-threatening disease requiring systemic immunosuppression, with one refractory to multiple immunosuppressants. The remaining patients were treated conservatively. TSH-receptor antibody (TRAb) levels were significantly raised in all cases, when ascertained. We report sight-threatening as well as mild TED in MS patients after treatment with alemtuzumab. Endocrine instability, radioiodine treatment and positive TRAb are all likely risk factors. The data support at least 6-monthly biochemical and clinical assessment with a low threshold for referral to an ophthalmologist, particularly for those with higher TRAb levels who may be at greater risk of orbitopathy.
\end{abstract}

\section{Introduction}

Alemtuzumab (Lemtrada; Campath-1H) is a humanised monoclonal antibody developed in Cambridge to target cells expressing CD52 [1]. This membrane glycoprotein is found on almost all mature leucocytes but critically not on their haematopoeitic precursor stem cells, allowing for a 'reboot' of the immune system with rapid depletion and

Rachna Murthy

rachna.murthy@addenbrookes.nhs.uk

rm943@cam.ac.uk

1 Thyroid Eye Disease Service, Department of Ophthalmology, Cambridge University Hospitals NHS Foundation Trust,

Cambridge, UK

2 Department of Clinical Neurosciences, University of Cambridge, Cambridge, UK

3 Wellcome-MRC Institute of Metabolic Science, Cambridge, UK gradual reconstitution of the immune system [2]. This has made it a helpful agent in the treatment of B-cell chronic lymphocytic leukaemia [3], organ transplantation [4, 5], vasculitides [6], uveitis [7, 8] and most recently as an effective treatment for multiple sclerosis (MS) [9]. It has been shown to decrease both the annualised relapse rate as well as reduce the overall accumulation of disability compared with interferon beta-1a treatment $[10,11]$.

The drug is administered intravenously over two courses: $12 \mathrm{mg} /$ day for 5 consecutive days, followed by the same dose for 3 consecutive days 12 months later; additional courses may be considered. Despite a drug half-life of less than a week [12], treatment results in a rapid depletion of circulating lymphocytes which can persist for several years; median recovery of $\mathrm{CD} 4+$ cells took 35 months [2], whilst B cells returned within 7 months but continued to rise, reaching $124 \%$ of baseline 27 months post treatment [13]. These temporal changes are likely significant for pathogenesis and will be discussed later. 
Alemtuzumab is also associated with side effects, such as infusion reactions and infections [14]. However, the principal adverse effect is the development of secondary autoimmunity during immune reconstitution, occurring in 12$48 \%$ of treated patients $[15,16]$. Reported cases have included Goodpasture's syndrome and fatal idiopathic thrombocytopenic purpura, but thyroid autoimmunity is the most common by far representing up to $77 \%$ of the cases of autoimmunity [17].

The onset of Graves' disease or other thyroid dysfunction peaked at 3 years post treatment but could occur as early as 6 months after treatment or as late as 7 years thereafter [18]. More than $96 \%$ of the patients were positive for TRAb [14]. Whilst MS may confer a higher risk of developing Graves' disease, the incidence is only around 1-2\% [19, 20] and therefore an order of magnitude smaller than that reported after alemtuzumab treatment. Furthermore, patients treated with interferon had a rate of only around $3 \%$. A causative link to alemtuzumab treatment was therefore quickly established.

Development of thyroid eye disease is less common, occurring in less than $2 \%$ of alemtuzumab-treated MS patients [21]. Consequently, only a handful of cases have been reported in the literature (see Table 2) [22-24]. These have ranged from the mild, requiring no treatment, to more serious disease manifestations requiring orbital wall decompression.

Until recently, no associations had been found between the risk of developing autoimmunity and the severity of MS, treatment response, total dosage or intervals between treatment, immune status or reconstitution speed [15, 22]. Neither increasing age nor sex played a role; however, as is the case for non-alemtuzumab-associated TED, smoking was found to predispose (threefold greater risk), as was family history (sevenfold greater risk) [13, 25].

As part of its development, alemtuzumab has been administered at our hospital since 1991 [26] and thereafter in the many phase II and III studies which have helped to confirm a sustained lower annualised relapse rate and reduced accumulation of disability compared to other treatments $[10,11]$. As the local dedicated thyroid eye disease service, we therefore are able to present the largest case series of alemtuzumab-induced thyroid orbitopathy and to provide an update on recommendations for monitoring and treatment.

\section{Methods}

We searched our bespoke electronic medical ophthalmology database for all patients with MS treated with alemtuzumab (Campath-1H) who were referred to the ophthalmology department for evaluation for thyroid eye disease between
1991 and 2018. Serum-free T4 (FT4), free T3 (FT3) and TSH were measured using the ADVIA Centaur (Siemens, Munich, Germany) standard automated immunoassay systems. Over the three decades of this study, TRAb levels were first assayed using a first-generation ELISA assay, and later replaced by the LUMItest TRAK assay from 2002 onwards. It has an upper accurately quantifiable limit of 40 IU/L (with levels greater than this being reported as $>40$ IU/L). Anti-TPO antibody was measured using a variety of standard commercially available assays over the study period.

\section{Cases}

Out of 162 patients with MS who had been treated with alemtuzumab in Cambridge, 71 developed thyroid dysfunction [27]. Of these, we identified ten patients who were subsequently found to have developed thyroid eye disease (14\%). Of these, only six were felt to require review by our ophthalmology department as the other four were patients from outside our region who only attended our hospital for the clinical trials. They had only a very mild eye disease and were instead offered a review by their local units.

The six patients seen in our clinic are summarised in Table 1. None of them had a family history of endocrine disease. Three were non-smokers at the time of developing ocular signs and symptoms. Five had significantly raised TRAb (> $20 \mathrm{IU} / \mathrm{L}$, reference range $<1 \mathrm{IU} / \mathrm{L}$ throughout) at presentation with eye disease-the sixth presented at a time prior to this test being routinely available in the hospital. Unusually, there was a 2:1 ratio of males to females. Two developed active orbitopathy following radioiodine $\left({ }^{131} \mathrm{I}\right)$ ablation of the thyroid gland-without steroid cover-for their Graves' disease. One case occurred with relapse of Graves' after cessation of anti-thyroid drug treatment and the resulting endocrine instability as the likely trigger. Three patients required systemic immunosuppression for sightthreatening disease, with the other three being managed conservatively. Their disease courses are summarised briefly below (Table 1).

Case 1: This 36-year-old man developed TED 26 months after his last alemtuzumab infusion and 10 years after his MS diagnosis. At presentation, he had pain on eye movement but only mild TED which did not require immunosuppression. TRAb was very elevated (>40 IU/L). Endocrine control was achieved with a combination of carbimazole and thyroxine medication, with slight reduction of his TRAb, 24 months after disease onset.

Case 2: A 47-year-old man presented with sightthreatening disease 20 months after alemtuzumab treatment and 6 years after his MS diagnosis. He had marked proptosis with corneal exposure and compressive optic neuropathy with red desaturation. With a clinical activity 


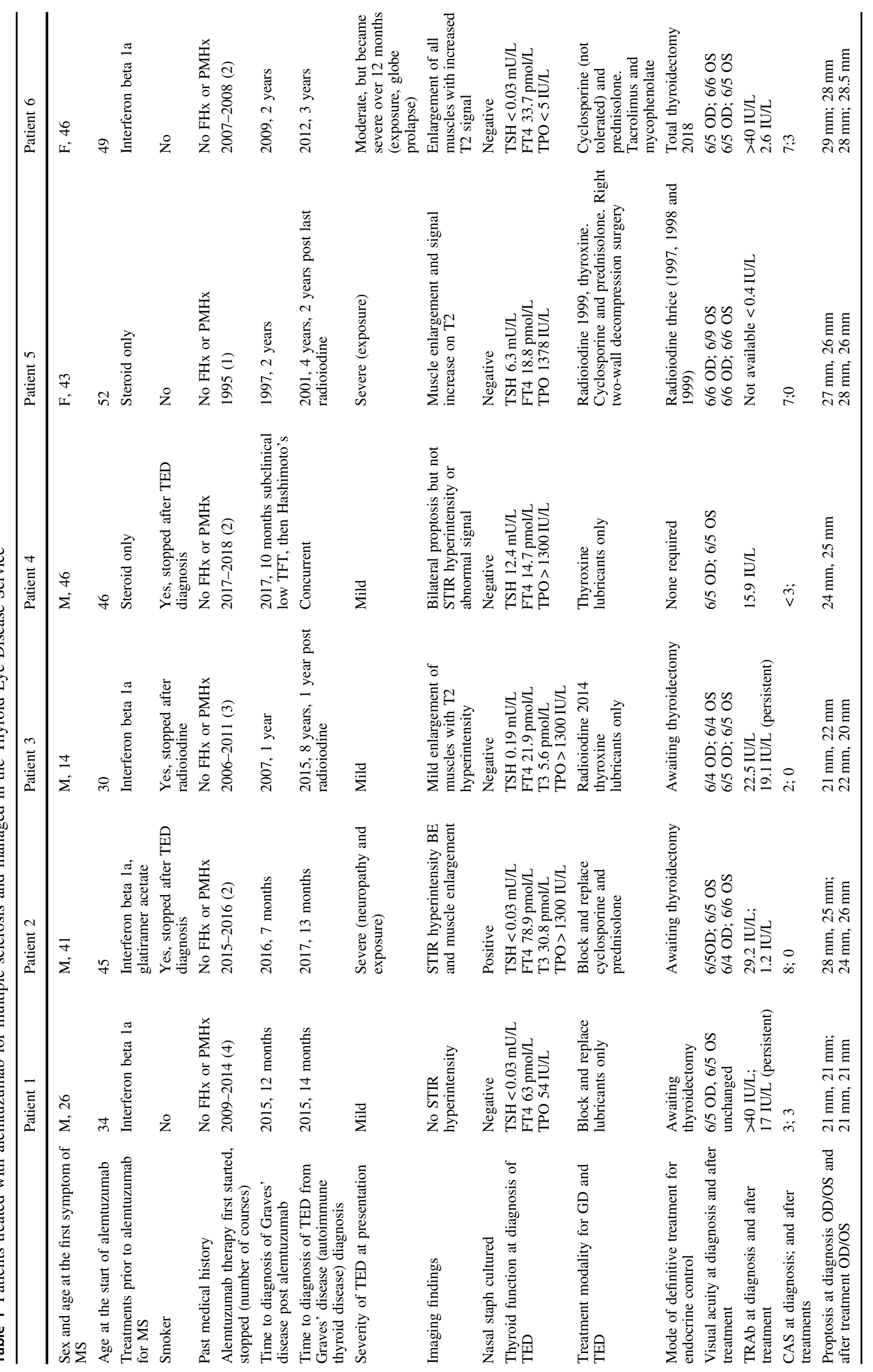



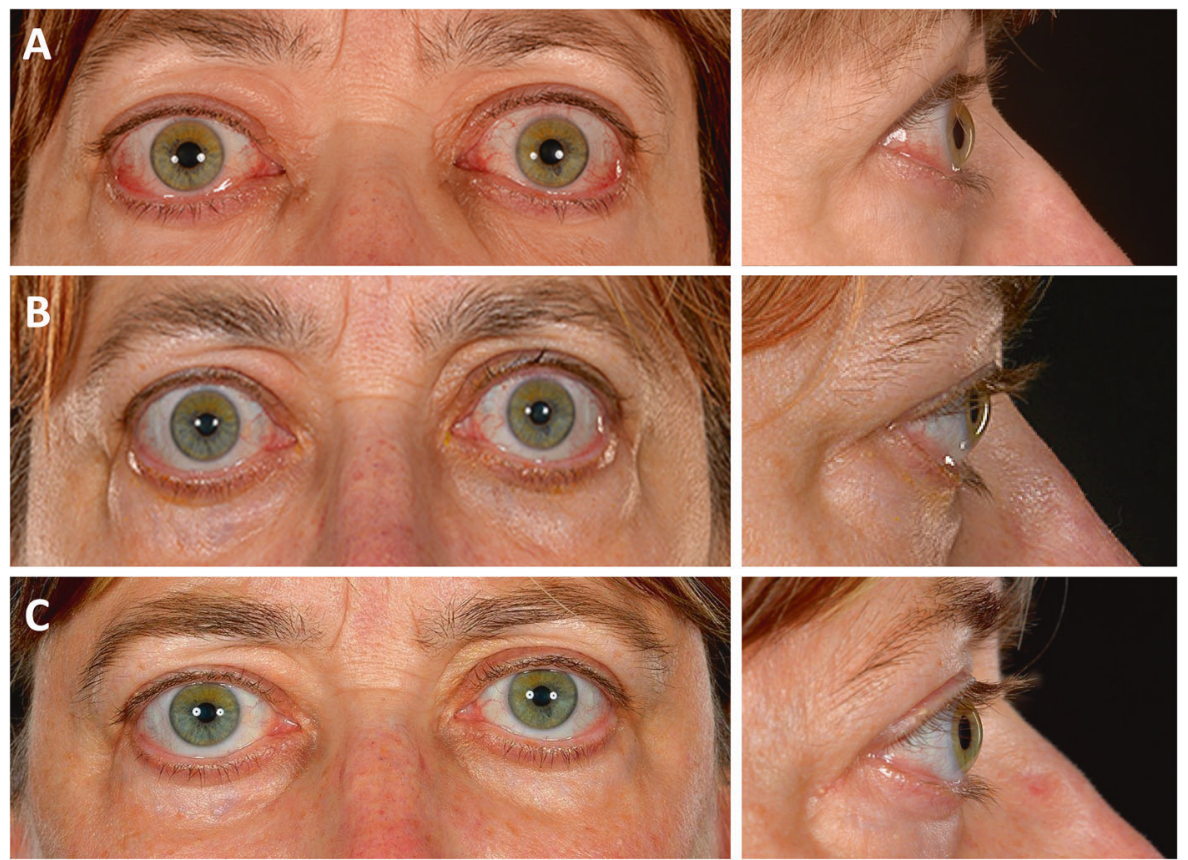

Fig. 1 Patient \#6 shown at presentation (a) with a CAS of 7 and active orbitopathy, lid retraction, firm orbits, mild proptosis, chemosis, bilateral upgaze restriction, reduced binocular field, and early optic neuropathy (with reduced colour by four Ishihara plates and reduced vision to 6/12). The TRAb level was $>40 \mathrm{IU} / \mathrm{L}$. Three years later (panel b) and following systemic immunosuppression with i.v.

score (CAS) [28] of 10 he was started on treatment with ciclosporin, i.v. methylprednisolone and prednisolone according to the Cambridge regimen [29]. At presentation his TRAb was significantly elevated at $29 \mathrm{IU} / \mathrm{L}$ but normalised by 9 months at which time his CAS was zero. He is now awaiting definitive treatment of Graves' thyrotoxicosis.

Case 3: A 39-year-old male ex-smoker presented with mild TED associated with high TRAb post ${ }^{131}$ I radioiodine ablation. This was 4 years after his last alemtuzumab treatment. His TED settled with lubricants only.

Case 4: A 46-year-old male smoker presented with mild TED in the context of high TRAb 10 months after treatment with alemtuzumab. Since he was hypothyroid [TSH 12.4 $\mathrm{mU} / \mathrm{L}(0.35-5.5 \mathrm{mU} / \mathrm{L})$, FT4 $14.7 \mathrm{pmol} / \mathrm{L}$ (10-19.8 pmol/ L)] it was felt that the TRAb was most likely blocking in nature. He was managed with lubricants and thyroxine and remains under follow up.

Case 5: A 54-year-old woman developed severe sightthreatening TED two years after her third radioiodine treatment for Graves' disease and 4 years post alemtuzumab. She had severe corneal exposure and was treated with the Cambridge regimen detailed above as well as requiring right two-wall decompression. There were no TRAb measurements in use clinically at the time of her presentation but subsequent assays shows that it has remained undetectable for years. methylprednisolone, oral prednisolone and cyclosporine she had a CAS of 3 and TRAb of $0.4 \mathrm{IU} / \mathrm{L}$. Acuity was restored to $6 / 6$ with a full Ishihara and reduction in proptosis. Ciclosporin was substituted for tacrolimus and mycophenolate mofetil due to side effects. Following thyroidectomy (c) the patient remained well; CAS of 0 and no lagophthalmos. Proptosis persisted at $28 \mathrm{~mm}$

Case 6: A 54-year-old woman presented 48 months after alemtuzumab treatment with moderately severe TED (CAS 7), which became increasingly severe over the next 12 months with sight-threatening exposure and globe prolapse (Fig. 1). TRAb at diagnosis was very elevated ( $>40$ IU/L). She was immunosuppressed on the Cambridge regimen but her pain worsened, so tacrolimus and mycophenolate mofetil replaced the ciclosporin. Her TED proved difficult to control-in fact she has been one of the most challenging patients treated in Cambridge to date. Her TRAb improved over a year but reduction in disease activity on imaging only occurred 3 years later (Fig. 2). Now, 5 years after presentation, her CAS is 3 and she has opted for elective thyroidectomy with steroid cover as a definitive treatment of Graves' thyrotoxicosis.

\section{Discussion}

Alemtuzumab-related Graves' disease has been characterized as having an "indolent" course [27] and most cases of the associated TED had been thought of as equally mild. However, our data confirms that immune reconstitution post alemtuzumab can trigger sight-threatening disease in two out of ten patients. Our patients exhibited the full spectrum of TED severity ranging from mild to severe disease 
Fig. 2 Coronal MRI STIR sequence of patient \#6 at presentation (a), exhibiting enlarged and hyper-intense signal in all extraocular muscles coupled with orbital fat oedema. This has caused proptosis, optic nerve stretch and orbital apex crowding as shown in the axial MRI with T2 weighting (b). Following immunomodulatory therapy, muscle size and signal intensity are improved (c; STIR sequence) and there is reduced crowding and nerve stretch $(\mathbf{d}$; axial T2 MRI)
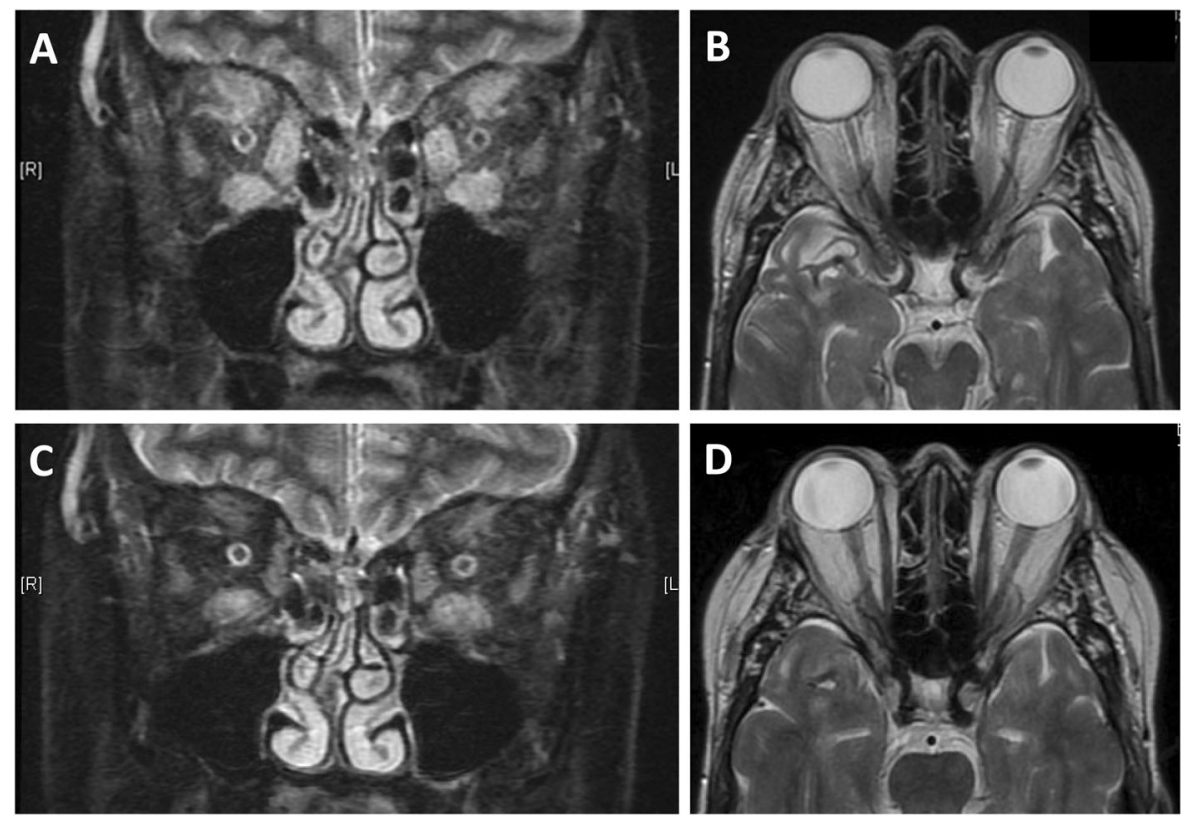

refractory to even powerful immunosuppressive regimens. We found a fluctuating and unpredictable course in these patients and a high frequency of TRAb-positive hypothyroidism following the hyperthyroidism. One can speculate that this may represent the underlying flux of the immune system during reconstitution.

Secondary thyroid autoimmunity and orbitopathy has also been described in other situations of immune reconstitution such as in HIV patients on highly active antiretroviral therapy [30-32] or following bone marrow transplantation [33]. Nevertheless alemtuzumab appears particularly prone to triggering this phenomenon. This is likely due to homoeostatic T-cell proliferation generating constantly activated and highly proliferative CD4+ and $\mathrm{CD} 8+$ populations which promote further inflammation [34]. IL-21 is a cytokine that has been strongly linked to a host of autoimmune diseases and is known to drive CD4+ and CD8 + T-cell proliferation as well as promoting B-cell survival and class-switching [35]. Studies have shown that higher circulating levels of IL-21 correlate with thyroid disease severity and increased risk of developing autoimmunity after alemtuzumab treatment [36]. The timing is also important: as alluded to earlier, median recovery of CD4+ cells took 35 months [2] whilst B-cells returned within 7 months and then rising to $124 \%$ of baseline 27 months post treatment [13].

The time course informs monitoring and management. Our six patients fit previous studies which report the onset of Graves' disease ranging from 6 months to 7 years but with a peak at around 18-36 months [15, 21] which coincides with when the B-cells are reconstituted and later peak.
It is likely sufficient, and also supported by the accumulated literature shown in Table 2, to discontinue monitoring for secondary autoimmunity after 5 years.

Taken together, we recommend at least six-monthly clinical reviews for alemtuzumab-treated patients coupled with serial measurements of TRAb for a period of up to 5 years post treatment. Clinicians should have a low threshold for ophthalmological assessment in patients with high TRAb levels [37], and particularly prior to considering definitive endocrine treatment with radioiodine. Two of our patients developed TED following ${ }^{131}$ I treatment - a known risk factor for progression and new TED [38]; our group has shown rise in TRAb following radioiodine ablation of the thyroid gland [39].

In this study, $14 \%$ of patients with alemtuzumab-induced Graves' disease subsequently developed thyroid eye disease. However, this is likely an underestimate as the patients did not undergo routine ophthalmological assessment and only those with obvious ophthalmic symptoms were referred to the TED service. As a result, subclinical and very mild TED may not have been recorded. As alemtuzumab is superior to conventional MS treatments it will be used widely. Ophthalmologists will benefit from being aware of the link with thyroid eye disease and how best to manage and monitor patients.

Acknowledgements The authors would like to thank Mr Cornelius Rene and Dr Paul Meyer for helpful discussions and insights into the management of thyroid eye disease over many years.

Funding There was no funding sought or obtained for this research. JJ is funded by the Wellcome Trust. 


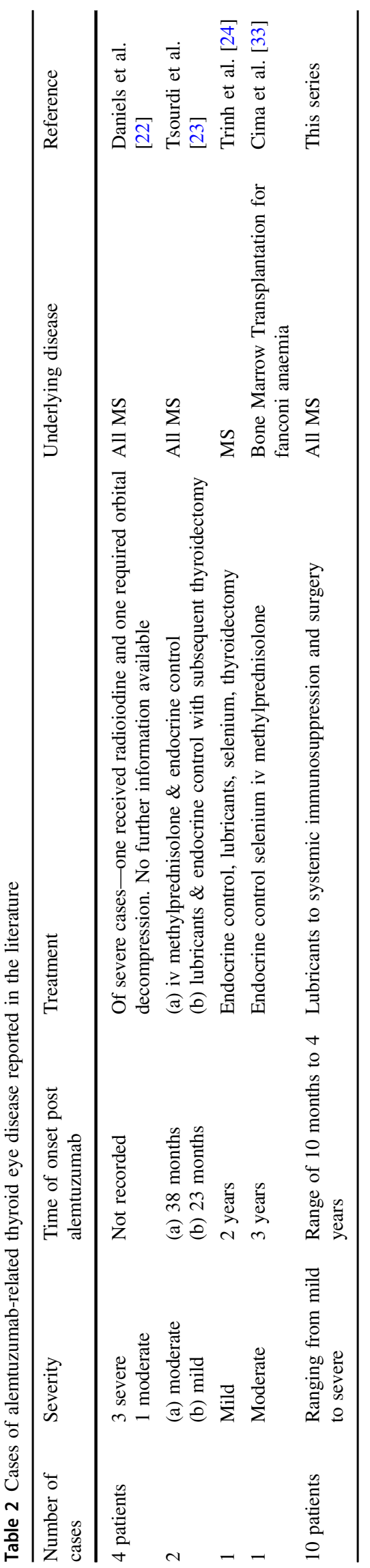

Author contributions All authors have contributed to the data collection and writing.

\section{Compliance with ethical standards}

Conflict of interest All authors are doctors who manage patients with thyroid disease, thyroid eye disease or multiple sclerosis. AJC received honoraria and speakers' fees from Sanofi, up until September 2017. JJ reports receiving speaker honoraria and consulting fees from Sanofi.

Ethics statement As an anonymised retrospective chart review no institutional review board authorisation was necessary.

Guarantor Dr Murthy serves as guarantor of this work. It is an honest, accurate, and transparent account of the study being reported; no important aspects of the study have been omitted.

License The corresponding author has the right to grant on behalf of all authors and does grant on behalf of all authors, an exclusive licence on a worldwide basis to permit this article to be published.

\section{References}

1. Greenwood J, Gorman SD, Routledge EG, Lloyd IS, Waldmann H. Engineering multiple-domain forms of therapeutic antibody CAMPATH-1H: effects on complement lysis. Ther Immunol. 1994;1:247-55.

2. Hill-Cawthorne GA, Button T, Tuohy O, Jones JL, May K, Somerfield J, et al. Long term lymphocyte reconstitution after alemtuzumab treatment of multiple sclerosis. J Neurol Neurosurg Psychiatry. 2012;83:298-304.

3. Osterborg A, Fassas AS, Anagnostopoulos A, Dyer MJ, Catovsky D, Mellstedt H. Humanized CD52 monoclonal antibody Campath-1H as first-line treatment in chronic lymphocytic leukaemia. Br J Haematol. 1996;93:151-3.

4. 3 C Study Collaborative Group, Haynes R, Harden P, Judge P, Blackwell L, Emberson J, Landray MJ, et al. Alemtuzumabbased induction treatment versus basiliximab-based induction treatment in kidney transplantation (the $3 \mathrm{C}$ Study): a randomised trial. Lancet. 2014;384:1684-90.

5. Clatworthy MR, Friend PJ, Calne RY, Rebello PR, Hale G, Waldmann $\mathrm{H}$, et al. Alemtuzumab (CAMPATH-1H) for the treatment of acute rejection in kidney transplant recipients: long-term follow-up. Transplantation. 2009;87:1092-5.

6. Walsh M, Chaudhry A, Jayne D. Long-term follow-up of relapsing/refractory anti-neutrophil cytoplasm antibody associated vasculitis treated with the lymphocyte depleting antibody alemtuzumab (CAMPATH-1H). Ann Rheum Dis. 2008;67:1322-7.

7. Isaacs JD, Hale G, Waldmann H, Dick AD, Haynes R, Forrester JV, et al. Monoclonal antibody therapy of chronic intraocular inflammation using Campath-1H. Br J Ophthalmol. 1995;79:1054-5.

8. Dick AD, Meyer P, James T, Forrester JV, Hale G, Waldmann $\mathrm{H}$, et al. Campath-1H therapy in refractory ocular inflammatory disease. Br J Ophthalmol. 2000;84:107-9.

9. Coles AJ, Twyman CL, Arnold DL, Cohen JA, Confavreux C, Fox EJ, et al. CARE-MS II investigators. Alemtuzumab for patients with relapsing multiple sclerosis after diseasemodifying therapy: a randomised controlled phase 3 trial. Lancet. 2012;380:1829-39. 
10. Coles AJ, Cohen JA, Fox EJ, Giovannoni G, Hartung HP, Havrdova E, et al. CARE-MS II and CAMMS03409 Investigators. Alemtuzumab CARE-MS II 5-year follow-up: efficacy and safety findings. Neurology. 2017;89:1117-26.

11. Havrdova E, Arnold DL, Cohen JA, Hartung HP, Fox EJ, Giovannoni $\mathrm{G}$, et al. CARE-MS I and CAMMS03409 Investigators. Alemtuzumab CARE-MS I 5-year follow-up: durable efficacy in the absence of continuous MS therapy. Neurology. 2017;89:1107-16.

12. Hale G, Rebello P, Brettman LR, Fegan C, Kennedy B, Kimby E, et al. Blood concentrations of alemtuzumab and antiglobulin responses in patients with chronic lymphocytic leukemia following intravenous or subcutaneous routes of administration. Blood. 2004;104:948-55.

13. Costelloe L, Jones J, Coles A. Secondary autoimmune diseases following alemtuzumab therapy for multiple sclerosis. Expert Rev Neurother. 2012;12:335-41.

14. CAMMS223 Trial Investigators, Coles AJ, Compston DA, Selmaj KW, Lake SL, Moran S, Margolin DH, et al. Alemtuzumab vs. interferon beta-1a in early multiple sclerosis. N Engl J Med. 2008;359:1786-801.

15. Cossburn M, Pace AA, Jones J, Ali R, Ingram G, Baker K, et al. Autoimmune disease after alemtuzumab treatment for multiple sclerosis in a multicenter cohort. Neurology. 2011;77:573-9.

16. Tuohy O, Costelloe L, Hill-Cawthorne G, Bjornson I, Harding K, Robertson N, et al. Alemtuzumab treatment of multiple sclerosis: long-term safety and efficacy. J Neurol Neurosurg Psychiatry. 2015;86:208-15.

17. Cohen JA, Coles AJ, Arnold DL, Confavreux C, Fox EJ, Hartung $\mathrm{HP}$, et al. CARE-MS I investigators. Alemtuzumab versus interferon beta 1a as first-line treatment for patients with relapsingremitting multiple sclerosis: a randomised controlled phase 3 trial. Lancet. 2012;380:1819-28.

18. Willis MD, Robertson NP. Alemtuzumab for multiple sclerosis. Curr Neurol Neurosci Rep. 2016;16:84.

19. De Keyser J. Autoimmunity in multiple sclerosis. Neurology. 1988;38:371-4.

20. Goris A, Pauwels I, Gustavsen MW, van Son B, Hilven K, Bos SD, et al. Genetic variants are major determinants of CSF antibody levels in multiple sclerosis. Brain. 2015; 138(Pt 3):632-43.

21. Moss HE. Visual consequences of medications for multiple sclerosis: the good, the bad, the ugly, and the unknown. Eye Brain. 2017;9:13-21.

22. Daniels GH, Vladic A, Brinar V, Zavalishin I, Valente W, Oyuela $\mathrm{P}$, et al. Alemtuzumab-related thyroid dysfunction in a phase 2 trial of patients with relapsing-remitting multiple sclerosis. J Clin Endocrinol Metab. 2014;99:80-9.

23. Tsourdi E, Gruber M, Rauner M, Blankenburg J, Ziemssen T, Hofbauer LC. Graves' disease after treatment with alemtuzumab for multiple sclerosis. Horm (Athens). 2015;14:148-53.

24. Trinh T, Haridas AS, Sullivan TJ. Ocular findings in alemtuzumab (Campath-1H)-induced thyroid eye disease. Ophthalmic Plast Reconstr Surg. 2016;32:e128-e129.

25. Aranha AA, Amer S, Reda ES, Broadley SA, Davoren PM. Autoimmune thyroid disease in the use of alemtuzumab for multiple sclerosis: a review. Endocr Pract. 2013;19:821-8.
26. Moreau T, Thorpe J, Miller D, Moseley I, Hale G, Waldmann H, et al. Preliminary evidence from magnetic resonance imaging for reduction in disease activity after lymphocyte depletion in multiple sclerosis. Lancet. 1994;30:344. 298-301

27. Pariani N, Willis M, Muller I, Healy S, Nasser T, McGowan A, et al. Alemtuzumab-induced thyroid dysfunction exhibits distinctive clinical and immunological features. J Clin Endocrinol Metab. 2018;103:3010-8.

28. Mourits MP, Koornneef L, Wiersinga WM, Prummel MF, Berghout A, van der Gaag R. Clinical criteria for the assessment of disease activity in Graves' ophthalmopathy: a novel approach. Br J Ophthalmol. 1989;73:639-44.

29. Meyer PA. Avoiding surgery for thyroid eye disease. Eye (Lond). 2006;20:1171-7.

30. Edmunds MR, Mellington F, Ford RL, Torlinska B, Manavi K, Boelaert K. Clinical challenges of thyroid eye disease in HIVpositive patients on highly active antiretroviral therapy. J Clin Endocrinol Metab. 2015;100:779-87.

31. Chen F, Day SL, Metcalfe RA, Sethi G, Kapembwa MS, Brook MG, et al. Characteristics of autoimmune thyroid disease occurring as a late complication of immune reconstitution in patients with advanced human immunodeficiency virus (HIV) disease. Med (Baltim). 2005;84:98-106.

32. Jubault V, Penfornis A, Schillo F, Hoen B, Izembart M, Timsit J, et al. Sequential occurrence of thyroid autoantibodies and Graves' disease after immune restoration in severely immunocompromised human immunodeficiency virus-1-infected patients. J Clin Endocrinol Metab. 2000;85:4254-7.

33. Cima LN, Lambrescu IM, Stejereanu L, Colita A, Or R, Fica S. Graves' orbitopathy after allogeneic bone marrow transplantation in a patient with Fanconi anemia - side effect of alemtuzumab therapy? Clin Case Rep. 2018;6:867-70.

34. Jones JL, Thompson SA, Loh P, Davies PL, Tuohy OC, Curry AJ, et al. Human autoimmunity after lymphocyte depletion is caused by homeostatic T-cell proliferation. Proc Natl Acad Sci USA. 2013;110:20200-5.

35. Liu SM, King C. IL-21-producing Th cells in immunity and autoimmunity. J Immunol. 2013;191:3501-6.

36. Jones JL, Phuah CL, Cox AL, Thompson SA, Ban M, Shawcross J, et al. IL-21 drives secondary autoimmunity in patients with multiple sclerosis, following therapeutic lymphocyte depletion with alemtuzumab (Campath-1H). J Clin Invest. 2009;119:2052-61.

37. Muller I, Willis M, Healy S, Nasser T, Loveless S, Butterworth S, et al. Longitudinal characterization of autoantibodies to the thyrotropin receptor (TRAb) during alemtuzumab therapy; evidence that TRAb may precede thyroid dysfunction by many years. Thyroid. 2018. https://doi.org/10.1089/thy.2018.0232. [Epub ahead of print]

38. Stein JD, Childers D, Gupta S, Talwar N, Nan B, Lee BJ, et al. Risk factors for developing thyroid-associated ophthalmopathy among individuals with Graves' disease. JAMA Ophthalmol. 2015;133:290-6.

39. Roos JC, Paulpandian V, Murthy R. Serial TSH-receptor antibody levels to guide the management of thyroid eye disease: the impact of smoking, immunosuppression, radio-iodine, and thyroidectomy. Eye (Lond). 2019 https://doi.org/10.1038/s41433-0180242-9. [Epub ahead of print]. 